\title{
The Impact of Obesity on the Left Ventricular Ejection Fraction Using Echocardiography
}

\author{
Bahaaedin A. Elkhader ${ }^{1 *}$, Alsafi A. Abdulla1, Mohammed A. Ali Omer ${ }^{1,2}$, Maram A. Fagiri, \\ Mustafa Z. Mahmoud ${ }^{3,4}$ \\ ${ }^{1}$ Radiotherapy and Nuclear Medicine Department, College of Medical Radiological Sciences, Sudan University \\ of Science and Technology, Khartoum, Sudan \\ ${ }^{2}$ Department of Radiologic Technology, College of Applied Medical Sciences, Qassim University, Buraidah, KSA \\ ${ }^{3}$ Radiology and Medical Imaging Department, College of Applied Medical Sciences, Salman bin Abdulaziz \\ University, Al-Kharj, KSA \\ ${ }^{4}$ Basic Sciences Department, College of Medical Radiological Sciences, Sudan University of Science and \\ Technology, Khartoum, Sudan \\ Email: ${ }^{*}$ dr.elkhaderali@gmail.com
}

Received 22 September 2014; revised 20 October 2014; accepted 18 November 2014

Copyright (C) 2014 by authors and Scientific Research Publishing Inc.

This work is licensed under the Creative Commons Attribution International License (CC BY).

http://creativecommons.org/licenses/by/4.0/

(c) (i) Open Access

\section{Abstract}

Global left ventricle chamber function in obese patients is assessed, most commonly, by means of the ejection fraction. The preferred noninvasive modality for evaluating regional wall motion and overall ventricular performance is usually color-flow Doppler transthoracic echocardiography. The aim of this study was to evaluate the relationship of left ventricular ejection fraction to body mass index (BMI) measure of obesity in obese patients by using echocardiography. A prospective cohort study was conducted in the period of July 2012 to September 2014 in the ultrasound department of the Sudan Heart Center in Khartoum-Sudan, among a group of 250 obese participants of acute myocardial infarction (AMI) $(67.2 \%$ males and $32.8 \%$ females) and their ages range from 22 to 86 years; mean age of $41 \pm 1.2$ years. Echocardiography studies were performed using MyLab 50 XVision-Esaote echocardiography machine equipped with $2.5 \mathrm{MHz}$ phased array probe. Standard Statistical Package for the Social Sciences (SPSS) was used to analyze the results. The mean BMI was $28.6 \pm 5.4 \mathrm{~kg} / \mathrm{m}^{2}$. Significant relationship is found between left ventricle ejection fraction and BMI $(P<0.001)$. BMI is a useful statistical tool to track the body size trends in a multicentric population in Sudan. Left ventricular ejection fraction allows ventricular function to be assessed without the need for further body size adjustment.

\footnotetext{
*Corresponding author.
}

How to cite this paper: Elkhader, B.A., Abdulla, A.A., Ali Omer, M.A., Fagiri, M.A. and Mahmoud, M.Z. (2014) The Impact of Obesity on the Left Ventricular Ejection Fraction Using Echocardiography. Open Journal of Medical Imaging, 4, $172-177$. 


\section{Keywords}

\section{Acute Myocardial Infarction (AMI), Body Mass Index (BMI), Echocardiography, Ejection Fraction}

\section{Introduction}

Acute myocardial infarction (AMI) is the most common contributor of morbidity and mortality worldwide [1]. Overweight and obesity have become increasingly common; worldwide, at least 1.1 billion adults are overweight and 312 million are obese, when overweight and obesity are defined conventionally as having a body mass index (BMI) of $25 \mathrm{~kg} / \mathrm{m}^{2}$ and $30 \mathrm{~kg} / \mathrm{m}^{2}$, respectively [2]. Surprisingly, obesity is a chronic disease that is often neglected and frequently not even thought of as a serious, life threatening condition [3] [4].

In general, population, overweight and obesity are associated with increased risk of developing cardiovascular disease, and thus it is not surprising that in cohorts of patients with the prevalent ischemic heart disease or acute coronary events, well over $50 \%$ are overweight or obese [5]-[8]. This relation could be due to the higher prevalence of diabetes, hypertension, and hypercholesterolemia observed in obese patients, but these data are derived mainly from high income countries. Although most of the global burden of cardiovascular disease is in developing countries, few data are available for the effect of obesity in these populations [9]-[11].

The diagnosis of an AMI is typically based upon the history, electrocardiogram, and cardiac enzymes, particularly serum troponins and creatine kinase fraction. Although not routinely performed for diagnosis, echocardiography is an accurate, noninvasive test that is able to detect evidence of myocardial ischemia or necrosis [12] [13].

The left ventricular ejection fraction after AMI is an important marker for mortality [14] [15]. The left ventricular ejection fraction may be assessed by nuclear imaging, magnetic resonance imaging and echocardiography [16]-[18]. Nuclear imaging and magnetic resonance imaging provide relatively reliable information and with acceptable intra and inter observer variability [19] [20]. However, the use of these imaging modalities is limited by radiation exposure during nuclear imaging, high costs and non availability in the coronary care unit and catheterization laboratory. Echocardiography is currently the most frequently used imaging modality for the assessment of left ventricular ejection fraction [17].

This study was designed with an aim to evaluate the relationship of left ventricular ejection fraction to body mass index (BMI) measure of obesity in obese patients using echocardiography.

\section{Materials and Methods}

\subsection{Study Design and Population}

This prospective cohort study was performed in the period of July 2012 to September 2014. Participants were scanned in the ultrasound department of the Sudan Heart Center in Khartoum, Sudan. Prior to participants scanning, a formal approval was obtained from Ethics and Scientific Committee of Sudan Heart Center and has therefore been performed in accordance with the ethical standards laid down in the 1964 Declaration of Helsinki and all subsequent revisions. After the nature of the procedure was fully explained, informed consents were obtained from participants and the ultrasound department.

Extensive medical history, detailed physical examination and measures of body mass index (BMI) were performed for each participant. Participants were included on the basis that they were positive to left ventricular systolic dysfunction with an ejection fraction of $(\leq 40 \%)$ determined by echocardiographic assessment of left ventricular function. Hypertension, impaired glucose tolerance/diabetes, dyslipidemia and previously treated from AMI surgically participants were excluded.

\subsection{Technical Information Identifies}

Echocardiography studies were performed using MyLab 50 XVision-Esaote echocardiography machine equipped with 2.5 MHz phased array probe, with small footprint for peeking in between rib interspaces. A water soluble gel was used to produce airless contact between the transducer and the patient's chest. Printing facilities issued through digital graphic ultrasound printer (made by Sony Corporation, Japan), 100 V; 1.5 A; and 50/60 
Hz.

\subsection{Cardiac Ultrasound Scanning Techniques}

While the patient is in the recumbent position, the transducer was placed in the fourth intercostal space at the left sternal border and directed posteriorly, laterally, and inferiorly to obtain a group of strong echoes from the posterior left ventricular wall. These echoes were recognized by their characteristic motion anteriorly during ventricular systole and posteriorly during diastole [19] [20].

Left ventricular systolic function was assessed by calculation of the wall motion index (WMI). An estimate of left ventricular ejection fraction can be obtained by multiplying the wall motion index by 0.3 . In the present study, significant left ventricle systolic dysfunction was defined as WMI $\leq 1.4$ (left ventricle ejection fraction approximately $\leq 40)[21]$.

\subsection{Statistical Analysis}

Data were initially summarized as mean \pm SD in a form of comparison tables. Statistical analysis was performed using the standard Statistical Package for the Social Sciences (SPSS Inc., Chicago, IL, USA) version 15 for windows. $P$-value terms such as equal and less to be used for significance; $P$-value $(P<0.001)$ was considered to be significant.

\section{Results}

Study population comprised 250 obese participants (67.2\% males and 32.8\% females). Participants' ages ranged from 22 to 86 years; with a mean age of $(41 \pm 1.2)$ years (Table 1$)$.

Out of the examined participants, a total of 93 subjects (58 males and 35 females) were presented in the age group (70 - 86) years, representatives (37.2\%) of the population (Table 2). The age group of (50 - 59) years was the smallest and represented only (10.8\%) of the population (Table 2).

The mean BMI among participants was $28.6 \pm 5.4 \mathrm{~kg} / \mathrm{m}^{2}$ (Table 3). At (22.8\%) of participants BMI was $>19$ and $<25 \mathrm{~kg} / \mathrm{m}^{2},(36 \%)$ had a BMI of $>25$ and $<30 \mathrm{~kg} / \mathrm{m}^{2},(24.4 \%)$ showed BMI of $>30$ and $<35 \mathrm{~kg} / \mathrm{m}^{2}$ and (16.8\%) had a BMI $>35 \mathrm{~kg} / \mathrm{m}^{2}$ (Table 3 ).

The relation between BMI and left ventricle ejection fraction among obese participants was presented in (Table 4), where the obtained $P$-value shows a significant relationship between obesity and left ventricular ejection fraction (Table 4).

Table 1. Gender and age of participants.

\begin{tabular}{|c|c|c|c|}
\hline Variable & Age Range (years) & Mean \pm SD (years) & Percentage (\%) \\
\hline Age & $22-86$ & $41 \pm 1.2$ & 100 \\
\hline Variable & Male & Female & Percentage (\%) \\
\hline Gender & 168 & 82 & 100 \\
\hline
\end{tabular}

Table 2. Distribution of participants age (years).

\begin{tabular}{|c|c|c|c|c|}
\hline \multirow{2}{*}{ Age Ranges } & \multicolumn{2}{|c|}{ Gender } & \multirow{2}{*}{ Total } & \multirow{2}{*}{ Percentage (\%) } \\
\hline & Male & Female & & \\
\hline $22-39$ & 24 & 5 & 29 & 11.6 \\
\hline $40-49$ & 24 & 9 & 33 & 13.2 \\
\hline $50-59$ & 17 & 10 & 27 & 10.8 \\
\hline $60-69$ & 45 & 23 & 68 & 27.2 \\
\hline $70-86$ & 58 & 35 & 93 & 37.2 \\
\hline Total & 168 & 82 & 250 & 100 \\
\hline
\end{tabular}


Table 3. BMI ranges, frequency, percentage and mean \pm SD among participants..

\begin{tabular}{cccc}
\hline BMI $\left(\mathrm{kg} / \mathrm{m}^{2}\right)$ & Frequency & Percentage (\%) & Mean \pm SD \\
\hline$>19$ and $<25$ & 57 & 22.8 & $21.60 \pm 1.7$ \\
$>25$ and $<30$ & 90 & 36.0 & $26.97 \pm 1.7$ \\
$>30$ and $<35$ & 61 & 24.4 & $31.98 \pm 1.4$ \\
$>35$ & 42 & 16.8 & $36.92 \pm 1.9$ \\
Total & 250 & 100 & $28.60 \pm 5.4$ \\
\hline
\end{tabular}

Table 4. Left ventricular ejection fraction and BMI relationship.

\begin{tabular}{ccc}
\hline Ejection Fraction (\%) & BMI $\left(\mathrm{kg} / \mathrm{m}^{2}\right)$ & $P$-Value \\
\hline$\leq 40.02$ & $>19$ and $<25$ & $<0.001$ \\
$\leq 41.2$ & $>25$ and $<30$ & $<0.001$ \\
$\leq 42.08$ & $>30$ and $<35$ & $<0.001$ \\
$\leq 43.08$ & $>35$ & $<0.001$ \\
\hline
\end{tabular}

\section{Discussion}

The results of this study indicate that obesity is positively related to increase the ejection fraction of the left ventricle (Table 4). Obesity has been considered as a state of chronic volume overload because the heart is required to circulate blood through the large and relatively low resistance depot of adipose tissue. Early studies had suggested that obesity was associated with eccentric left ventricular remodeling. The results of cine cardiac magnetic resonance (CMR) study and other echocardiography studies instead now consistently show that both left ventricular cavity size and wall thickness may be increased in obese subjects with wall thickness increased to a greater extent than cavity size (concentric left ventricle remodeling) [22] [23]. Several studies have found that the left ventricle ejection fraction is normal to increase in the majority of obese subjects [22]-[24].

Iacobellis and Sharma [25] proposed uncomplicated obesity as those individuals with elevated BMI but with normal fasting glucose, glucose tolerance, systolic and diastolic blood pressures, lipid profile, resting electrocardiogram, and thyroid function, without a history of metabolic, cardiovascular, respiratory disease, and clinically significant abnormalities on physical examination. They reported that indexed left ventricle mass and left ventricular geometry in subjects with uncomplicated obesity $(n=75)$ were not significantly different from a lean control group $(n=60)$ [24]. In the present study, all participants were obese and without hypertension, impaired glucose tolerance/diabetes and dyslipidemia. Therefore, the concept of uncomplicated obesity was not useful in our study population due to the rare occurrence of this phenotype.

Determining the relationship between obesity and cardiac size is confounded by the known positive relationship of body size to left ventricular mass and volume. Body surface area is the most common index for cardiac size, but has been suggested to underestimate the impact of obesity on left ventricular mass and geometry [26]. Alternatively, indexing left ventricle mass to the 2.7 power of height has been reported to be appropriate for but has unknown applicability for CMR. For the Multi-Ethnic Study of Atherosclerosis (MESA) population, left ventricle mass indexed to the 2.7 power of height resulted in a higher proportion of left ventricle hypertrophy for shorter participants compared with taller participants [27], raising questions regarding the validity of this approach to our data (Table 3 and Table 4).

As a limitation, the authors didn't overcome this difficulty, because we looked at single measures of obesity by using body BMI, rather than other measures of obesity as waist circumference (WC), waist-to-hip ratio (WHR) and measures the association of fat mass (FM) with left ventricle size after controlling for fat-free mass.

\section{Conclusion}

In conclusion, BMI shows a significant association with myocardial infarction risk. BMI is a useful statistical 
tool to track the body size trends in Sudan. Left ventricular ejection fraction allows ventricular function to be assessed without the need for further body size adjustment. With BMI measures of obesity, ejection fraction showed a consistent change in relation to increased obesity levels.

\section{Acknowledgements}

The authors would like to thank the staff of the Ultrasound Department of the Sudan Heart Center for their cooperation and support during data collection.

\section{References}

[1] Antmen, E.M. and boaunwald, E. (2008) Acute MI. Harrison’s Principle of Internal Medicine. 17th Edition, McGrawHill Professional, New York.

[2] Haslam, D.W. and James, W.T. (2005) Obesity. Lancet, 366, 1197-1209. http://dx.doi.org/10.1016/S0140-6736(05)67483-1

[3] Frühbeck, G., Diez-Caballero, A., Gómez-Ambrosi, J., Cienfuegos, J.A. and Salvador, J. (2003) Preventing Obesity. Doctors Underestimate Obesity. BMJ, 326, 102-103. http://dx.doi.org/10.1136/bmj.326.7380.102

[4] Frühbeck, G. (2004) Screening and Interventions for Obesity in Adults. Annals of Internal Medicine, 141, 245-246. http://dx.doi.org/10.7326/0003-4819-141-3-200408030-00026

[5] Yusuf, S., Hawken, S., Ounpuu, S., Bautista, L., Franzosi, M.G., Commerford, P., Lang, C.C., Rumboldt, Z., Onen, C.L., Lisheng, L., Tanomsup, S., Wangai Jr., P., Razak, F., Sharma, A.M. and Anand, S.S. (2005) Obesity and the Risk of Myocardial Infarction in 27,000 Participants from 52 Countries: A Case-Control Study. Lancet, 366, 1640-1649. http://dx.doi.org/10.1016/S0140-6736(05)67663-5

[6] Calle, E.E., Thun, M.J., Petrelli, J.M., Rodriguez, C. and Heath, C.W. (1999) Body-Massindex and Mortality in a Prospective Cohort of U.S. Adults. The New England Journal of Medicine, 341, 1097-1105. http://dx.doi.org/10.1056/NEJM199910073411501

[7] Mehta, L., Devlin, W., McCullough, P.A., O’Neill, W.W., Skelding, K.A., Stone, G.W., Boura, J.A. and Grines, C.L. (2007) Impact of Body Mass Index on Outcomes after Percutaneous Coronary Intervention in Patients with Acute Myocardial Infarction. The American Journal of Cardiology, 99, 906-910. http://dx.doi.org/10.1016/j.amjcard.2006.11.038

[8] Steinberg, B.A., Cannon, C.P., Hernandez, A.F., Pan, W., Peterson, E.D. and Fonarow, G.C. (2007) Medical Therapies and Invasive Treatments for Coronary Artery Diseaseby Body Mass: The "Obesity Paradox" in the Get with the Guidelines Database. The American Journal of Cardiology, 100, 1331-1335.

http://dx.doi.org/10.1016/j.amjcard.2007.06.019

[9] Rea, T.D., Heckbert, S.R., Kaplan, R.C., Psaty, B.M., Smith, N.L., Lemaitre, R.N. and Lin, D. (2001) Body Mass Index and the Risk of Recurrent Coronary Events Following Acute Myocardial Infarction. The American Journal of Cardiology, 88, 467-472. http://dx.doi.org/10.1016/S0002-9149(01)01720-9

[10] Stevens, J., Cai, J., Pamuk, E.R., Williamson, D.F., Thun, M.J. and Wood, J.L. (1998) The Effect of Age on the Association between Body-Mass Index and Mortality. The New England Journal of Medicine, 338, 1-7.

http://dx.doi.org/10.1056/NEJM199801013380101

[11] Yusuf, S., Reddy, S., Ounpuu, S. and Anand, S. (2001) Global Burden of Cardiovascular Diseases: Part I: General Considerations, the Epidemiologic Transition, Risk Factors, and Impact of Urbanization. Circulation, 104, 2746-2753. http://dx.doi.org/10.1161/hc4601.099487

[12] Antman, E., Bassand, J.P., Klein, W., Ohman, M., Sendon, J.L., Rydén, L., Simoons, M. and Tendera, M. (2000) Myocardial Infarction Redefined-A Consensus Document of the Joint European Society of Cardiology/American College of Cardiology Committee for the Redefinition of Myocardial Infarction. Journal of the American College of Cardiology, 36, 959-969. http://dx.doi.org/10.1016/S0735-1097(00)00804-4

[13] Thygesen, K., Alpert, J.S. and White, H.D. (2007) Joint ESC/ACCF/AHA/WHF Task Force for the Redefinition of Myocardial Infarction. Universal Definition of Myocardial Infarction. European Heart Journal, 28, 2525-2538. http://dx.doi.org/10.1093/eurheartj/ehm355

[14] Pfeffer, M.A., Braunwald, E., Moye, L.A., Basta, L., Brown Jr., E.J., Cuddy, T.E., Davis, B.R., Geltman, E.M., Goldman, S., Flaker, G.C., Klein, M., Lamas, G.A., Packer, M., Roulean, J., Roulean, J.L., Rutherford, J., Wertheimer, J.H. and Hawkins, C.M. (1992) Effect of Captopril on Mortality and Morbidity in Patients with Left Ventricular Dysfunction after Myocardial Infarction-Results of the Survival and Ventricular Enlargement Trial. The SAVE Investigators. The New England Journal of Medicine, 327, 669-677. http://dx.doi.org/10.1056/NEJM199209033271001

[15] Volpi, A., De Vita, C., Franzosi, M.G., Geraci, E., Maggioni, A.P., Mauri, F., Negri, E., Santoro, E., Tavazzi, L. and 
Tongnoni, G. (1993) Determinants of 6-Month Mortality in Survivors of Myocardial Infarction after Thrombolysis. Results of the GISSI-2 Database. The Ad hoc Working Group of the Gruppo Italiano per lo Studio della Sopravvivenza nell’Infarto Miocardico (GISSI)-2 Data Base. Circulation, 88, 416-429. http://dx.doi.org/10.1161/01.CIR.88.2.416

[16] Senior, R., Sridhara, B.S., Basu, S., Henley, M., Handler, C.E., Raftery, E.B. and Lahiri, A. (1994) Comparison of Radionuclide Ventriculography and 2D Echocardiography for the Measurement of Left Ventricular Ejection Fraction Following Acute Myocardial Infarction. European Heart Journal, 15, 1235-1239.

[17] Ioannidis, J.P., Trikalinos, T.A. and Danias, P.G. (2002) Electrocardiogram-Gated Single-Photon Emission Computed Tomography versus Cardiac Magnetic Resonance Imaging for the Assessment of Left Ventricular Volumes and Ejection Fraction: A Meta-Analysis. Journal of the American College of Cardiology, 39, 2059-2068. http://dx.doi.org/10.1016/S0735-1097(02)01882-X

[18] McGowan, J.H. and Cleland, J.G. (2003) Reliability of Reporting Left Ventricular Systolic Function by Echocardiography: A Systematic Review of 3 Methods. American Heart Journal, 146, 388-397. http://dx.doi.org/10.1016/S0002-8703(03)00248-5

[19] Benjelloun, H., Cranney, G.B., Kirk, K.A., Blackwell, G.G., Lotan, C.S. and Pohost, G.M. (1991) Interstudy Reproducibility of Biplane Cine Nuclear Magnetic Resonance Measurements of Left Ventricular Function. American Journal of Cardiology, 67, 1413-1420. http://dx.doi.org/10.1016/0002-9149(91)90473-X

[20] Hyun, I.Y., Kwan, J., Park, K.S. and Lee, W.H. (2001) Reproducibility of Tl-201 and Tc-99 m Sestamibi Gated Myocardial Perfusion SPECT Measurement of Myocardial Function. Journal of Nuclear Cardiology, 8, 182-187. http://dx.doi.org/10.1067/mnc.2001.112753

[21] Kober, L., Torp-Pedersen, C., Carlsen, J., Videbaek, R. and Egeblad, H. (1994) An Echocardiographic Method for Selecting High Risk Patients Shortly after Acute Myocardial Infarction, for Inclusion in Multi-Centre Studies (as Used in the TRACE Study). Trandolapril Cardiac Evaluation. European Heart Journal, 15, 1616-1620.

[22] Powell, B.D., Redfield, M.M., Bybee, K.A., Freeman, W.K. and Rihal, C.S. (2006) Association of Obesity with Left Ventricular Remodeling and Diastolic Dysfunction in Patients without Coronary Artery Disease. American Journal of Cardiology, 98, 116-120. http://dx.doi.org/10.1016/j.amjcard.2006.01.063

[23] Fox, E., Taylor, H., Andrew, M., Han, H., Mohamed, E., Garrison, R. and Skelton, T. (2004) Body Mass Index and Blood Pressure Influences on Left Ventricular Mass and Geometry in African Americans: The Atherosclerotic Risk in Communities (ARIC) Study. Hypertension, 44, 55-60. http://dx.doi.org/10.1161/01.HYP.0000132373.26489.58

[24] Iacobellis, G., Ribaudo, M.C., Leto, G., Zappaterreno, A., Vecci, E., Di Mario, U. and Leonetti, F. (2002) Influence of Excess Fat on Cardiac Morphology and Function: Study in Uncomplicated Obesity. Obesity Research, 10, 767-773. http://dx.doi.org/10.1038/oby.2002.104

[25] Iacobellis, G. and Sharma, A.M. (2007) Obesity and the Heart: Redefinition of the Relationship. Obesity Reviews, 8, 35-39. http://dx.doi.org/10.1111/j.1467-789X.2006.00257.x

[26] Levy, D., Anderson, K.M., Savage, D.D., Kannel, W.B., Christiansen, J.C. and Castelli, W.P. (1988) Echocardiographically Detected Left Ventricular Hypertrophy: Prevalence and Risk Factors. The Framingham Heart Study. Annals of Internal Medicine, 108, 7-13. http://dx.doi.org/10.7326/0003-4819-108-1-7

[27] Turkbey, E.B., McClelland, R.L., Kronmal, R.A., Burke, G.L., Bild, D.E., Tracy, R.P., Arai, A.E., Lima, J.A. and Bluemke, D.A. (2010) The Impact of Obesity on the Left Ventricle: The Multi-Ethnic Study of Atherosclerosis (MESA). JACC: Cardiovascular Imaging, 3, 266-274. http://dx.doi.org/10.1016/j.jcmg.2009.10.012 
Scientific Research Publishing (SCIRP) is one of the largest Open Access journal publishers. It is currently publishing more than 200 open access, online, peer-reviewed journals covering a wide range of academic disciplines. SCIRP serves the worldwide academic communities and contributes to the progress and application of science with its publication.

Other selected journals from SCIRP are listed as below. Submit your manuscript to us via either submit@scirp.org or Online Submission Portal.
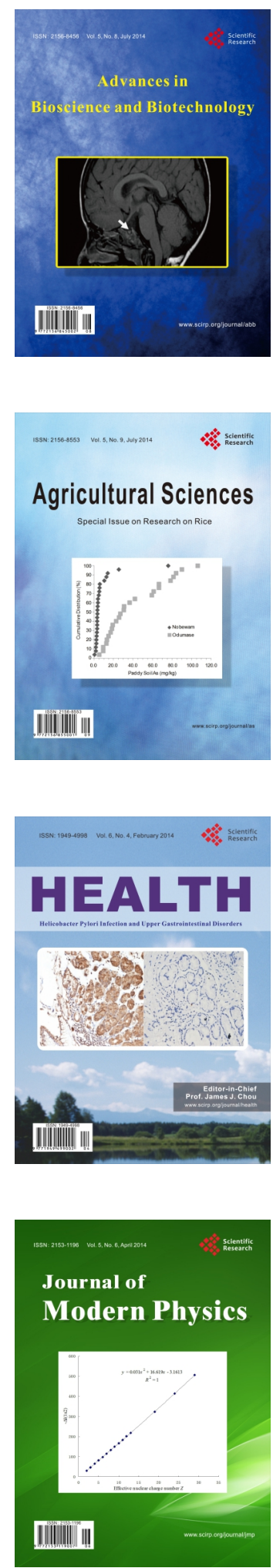
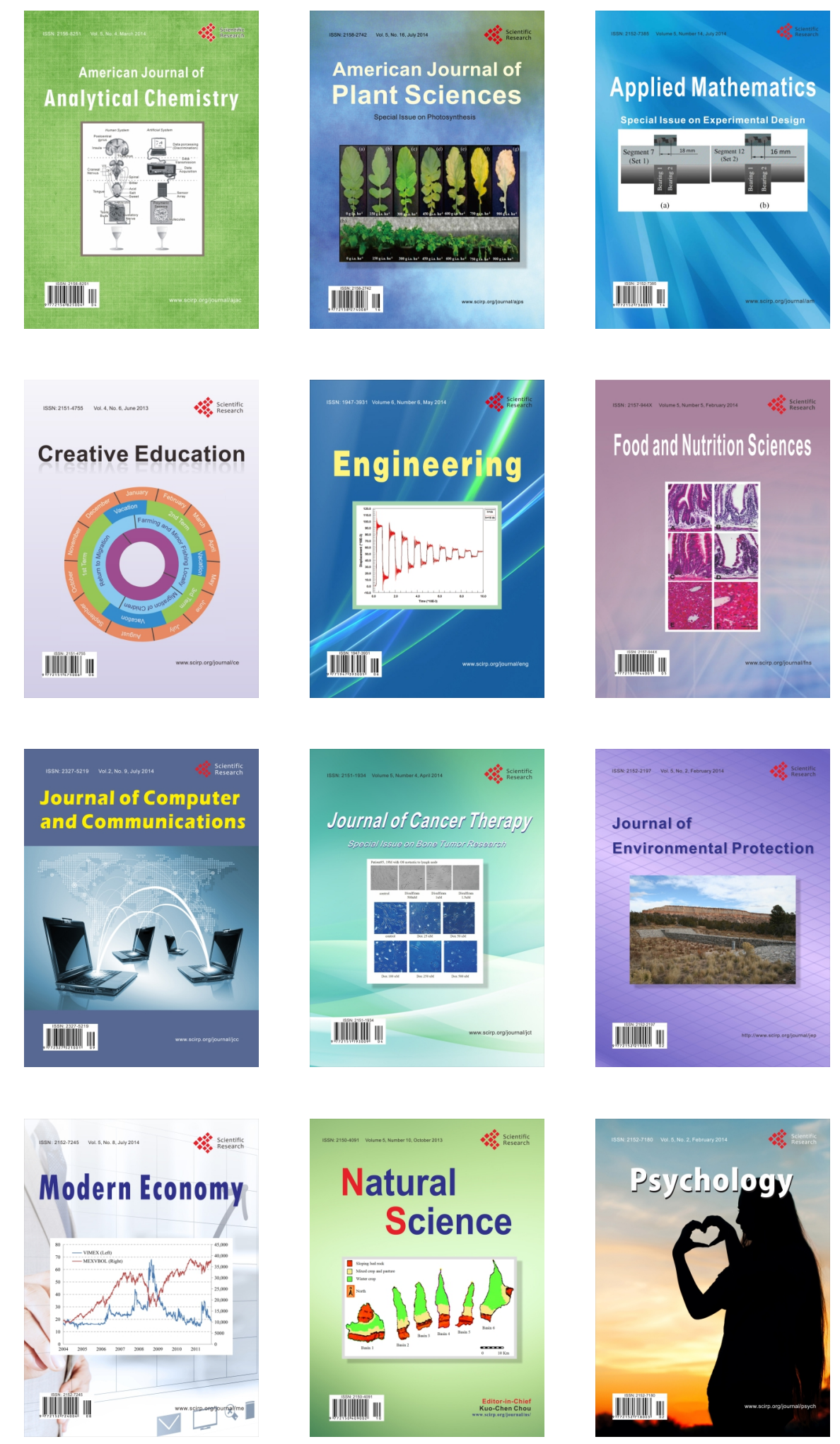